DOI: $10.20472 /$ IAC.2018.044.053

\title{
TOMOMASA YAMASAKI
}

Aoyama Gakuin University, Japan

TAKASHI KABURAGI

Aoyama Gakuin University, Japan

SATOSHI KUMAGAI

Aoyama Gakuin University, Japan

TOSHIYUKI MATSUMOTO

Aoyama Gakuin University, Japan

YOSUKE KURIHARA

Aoyama Gakuin University, Japan

\section{URINARY VOLUME PREDICTION METHOD BY GAUSSIAN PROCESS}

\begin{abstract}
:
Elderly people need some help for urination due to their muscle weakness. In certain cases, some elderly people need help more to go to bathroom on a regular basis because they cannot feel urinary urgency due to nerve dysfunction. Since the urination interval between urinations varies around ranging from 30 to 100 minutes in general, caregivers are required to check elderly people's urination at intervals around 30 minutes to prevent urinary incontinence even though no indication. If caregivers could predict long-term urinary volume transition in the bladder, they would be able to make well-organized excretion management plans to take the elderly people to the bathroom, and do other chores accordingly. However, the prediction of the urinary volume is difficult because the urinary accumulation patterns are dispersed due to the daily body condition. In this research, we proposed a prediction method for urinary volume in their bladder based on Gaussian Process from datasets which were measured using ultrasonic sensor. The ultrasonic sensor is used commonly in nursing homes, which is the reason why we used it for the proposed method.

In order to evaluate the proposed method, we conducted an experiment assessing its validity. The subjects were two male individuals in their mid-twenties (subject $A$ and subject $B$ ). One dataset contains time series between urinations. We measured 90 datasets from the subjects. In this experiment, datasets with urination interval of 70-100 minutes were defined as the long-term datasets. As the results of prediction, in the case of using both of short-term datasets and long-term datasets, the root mean square error (RMSE) for subject $A$ and $B$ were $76.70 \mathrm{ml}$, and $85.76 \mathrm{ml}$ respectively. Furthermore, in the case of using long-term datasets, the RMSE for subject $A$ and $B$ were $54.64 \mathrm{ml}$, and $58.20 \mathrm{ml}$ respectively. Comparing the results of both cases shows that the prediction applying only long-term datasets has higher accuracy.
\end{abstract}

\section{Keywords:}

Urinary Volume, Gaussian Process, Ultrasonic Sensor, Nursing Care, Excretion Management

JEL Classification: 110 